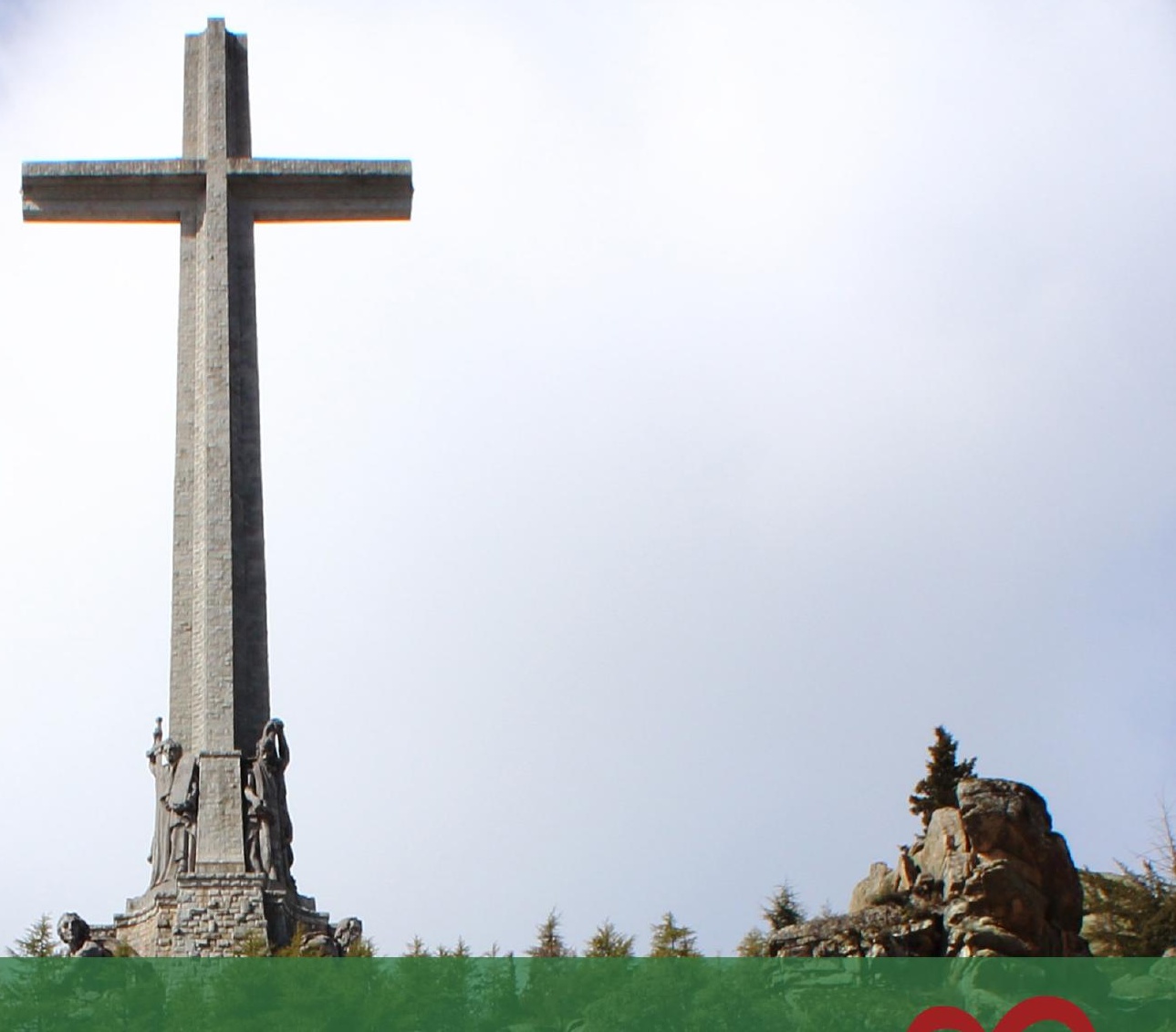

Revista digital de Ciencia y Didáctica de la Historia

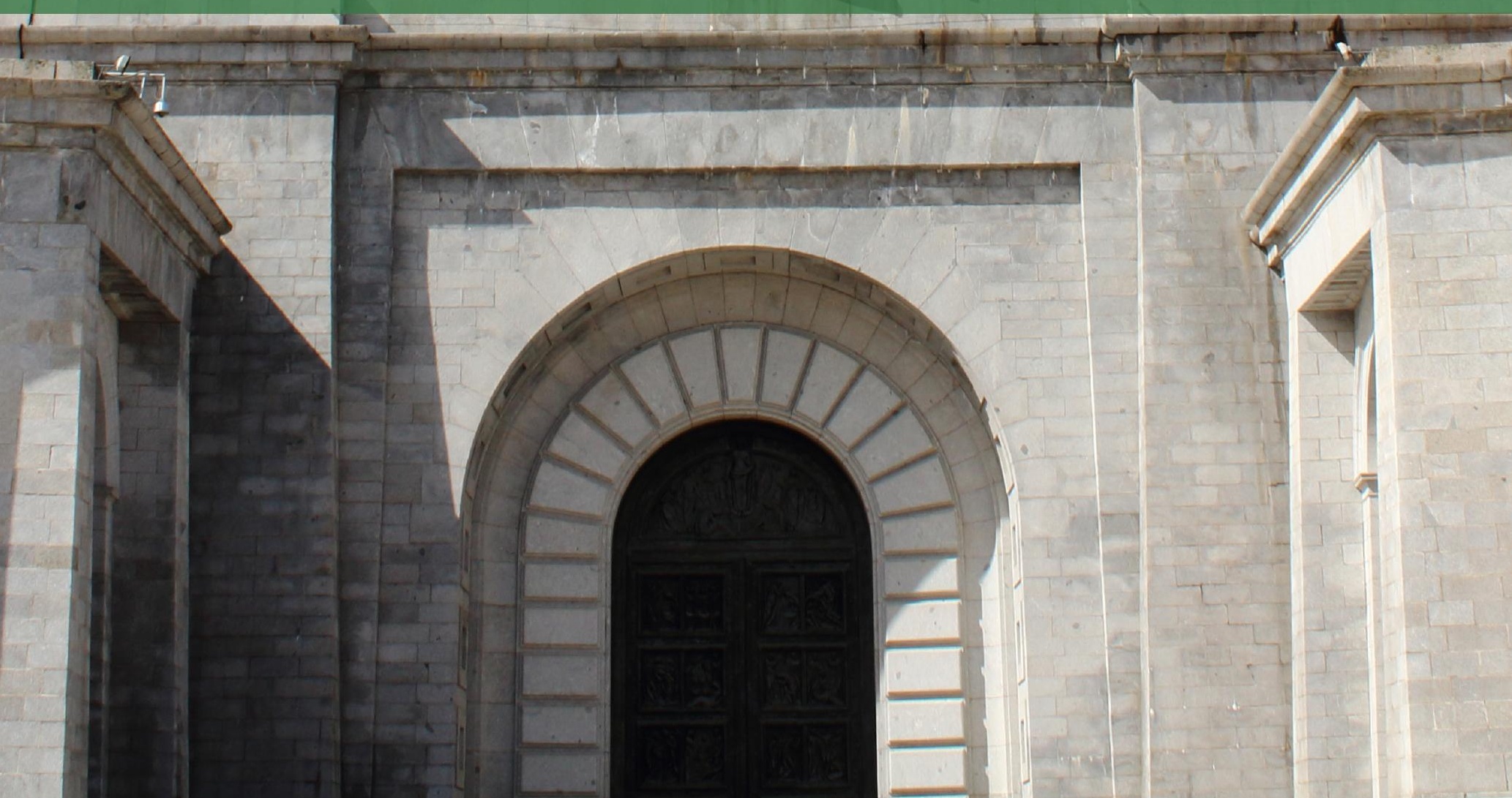




\section{Panta Rei \\ Revista Digital de Ciencia \\ y Didáctica de la Historia}

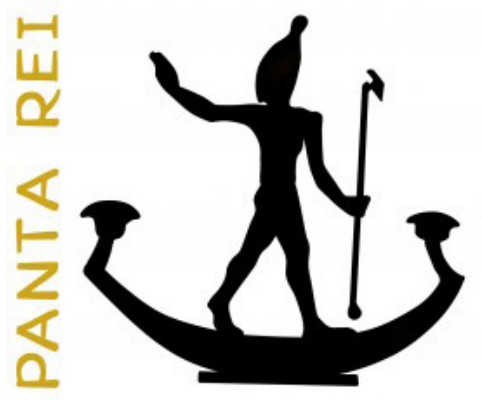

\section{8}

Revista anual

Fecha de inicio: 1995

Revista Panta Rei. pantarei@um.es

Edita:

Centro de Estudios del Próximo Oriente y la Antigüedad Tardía - CEPOAT

Edificio Universitario Saavedra Fajardo.

Universidad de Murcia

C/ Actor Isidoro Máiquez, 9

30007 - MURCIA - ESPAÑA

Teléfono: (+34) 868883890

cepoat@um.es

Web: www.um.es/cepoat/pantarei

Edición 2018

ISSNe: 2386-8864

ISSN: 1136-2464

Depósito legal: MU-966-1995

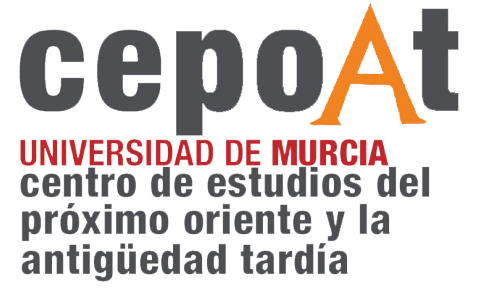

En Portada: Valle de los Caídos, Madrid. (Fotografía de: Adrián Rosell Lucas).

Responsables de los textos: Sus autores.

Responsable de la presente edición: Consejo Editorial Panta Rei. 


\section{CONSEJO DE REDACCIÓN}

\section{Coordinador editorial}

Egea Vivancos, Alejandro

[Didáctica de las Ciencias Sociales, UMU]

\section{Editores}

Botí Hernández, Juan Jesús

[CEPOAT, UMU]

Jiménez Vialás, Helena

[UMU]

López Muñoz, Damaris

[UJA]

Meseguer Gil, Antonio José

[CEPOAT, UNED]

Sáez Giménez, David Omar

[CEPOAT, UMU]

Sánchez Mondéjar, Celso Miguel

[Patrimonio Inteligente]

\section{Secretaria}

Arias Ferrer, Laura

[Didáctica de las Ciencias Sociales, UMU]

\section{Responsable informático}

Martínez García, José Javier

[CEPOAT, UMU]

\section{Traducción y corrección lingüística}

Martínez Martínez, Cristina

[Sociedad Española de Lenguas Modernas]

Albaladejo Albaladejo, Sara

[ISEN, UMU]

\section{CONSEJO ASESOR}

Adroher Auroux, Andrés María [Arqueología, Universidad de Granada]

Albero Muñoz, $\mathrm{M}^{\mathrm{a}}$ del Mar $\left[\mathrm{H} .^{\mathrm{a}}\right.$ del Arte, Universidad de Murcia]

Alia Miranda, Francisco [Historia Contemporánea, UCLM]

Arciniega García, Luis [Historia del Arte, Universidad de Valencia]
Barrio Barrio, Juan Antonio [Historia Medieval, Universidad de Alicante]

Castellano i Solé, Núria [Egiptología, Schola Didàctica Activa S.L.]

Chapman, Arthur [History Education, University College of London, Reino Unido]

Cid López, Rosa María [Historia Antigua, Universidad de Oviedo]

Cobacho López, Ángel [Derecho, Universidad de Murcia]

Cuenca López, José María [Didáctica de las Ciencias Sociales, Universidad de Huelva]

Egea Bruno, Pedro $\mathrm{M}^{\mathrm{a}}$ [Historia Contemporánea, Universidad de Murcia]

Feijoo Martínez, Santiago [Arqueología, Consorcio Ciudad Monumental de Mérida]

García Atienzar, Gabriel [Prehistoria, Universidad de Alicante]

Ginestí Rosell, Anna [Filología Clásica, Katholische Universität Eichstätt-Ingolstadt]

González Monfort, Neus [Didáctica de las Ciencias Sociales, Universidad Autónoma de Barcelona]

González Soutelo, Silvia [Arqueología, Universidad de Vigo]

Haber Uriarte, María [Prehistoria, Universidad de Murcia]

Hernández de la Fuente, David [Historia Antigua, Universidad Complutense]

Hutson, Scott R. [Anthropology, University of Kentucky, EEUU]

Igual Luis, David [Historia Medieval, UCLM]

Irigoyen López, Antonio [Historia Moderna, Universidad de Murcia]

Jover Maestre, Francisco Javier [Prehistoria, Universidad de Alicante]

Mahony, Simon [Digital Humanities, University College of London, Reino Unido]

Marsilla de Pascual, Francisco Reyes [Técnicas historiográficas, Universidad de Murcia]

Martínez-Burgos García, Palma [H. ${ }^{\text {a }}$ del Arte, UCLM]

Mathis, Christian [Didaktik der Geschichte, PH Zürich]

Miralles Maldonado, José Carlos [Filología Clásica, Universidad de Murcia]

Molina Gómez, José Antonio [Historia Antigua, Universidad de Murcia]

Mónica Ghirardi [Historia Moderna, Universidad Nacional de Córdoba, Argentina]

Navarro Espinach, Germán [Historia Medieval, Universidad de Zaragoza]

Noguera Celdrán, José Miguel [Arqueología, Universidad de Murcia]

Ortiz Heras, Manuel [Historia Contemporánea, UCLM]

Panzram, Sabine [Historia Antigua, Universität Hamburg]

Pérez Molina, Miguel Emilio [Filología Clásica, Universidad de Murcia]

Prados Martínez, Fernando [Arqueología, Universidad de Alicante]

Sánchez Ibáñez, Raquel [Didáctica de las Ciencias Sociales, Universidad de Murcia]

Sancho Gómez, Miguel Pablo [Educación, UCAM]

Victoria Moreno, Diego [Historia Contemporánea, UNED]

Vilar García, María José [Historia Contemporánea, Universidad de Murcia]

Vivas Sainz, Inmaculada [H. ${ }^{\text {a }}$ del Arte, UNED]

Zamora López, José Ángel [Próximo Oriente Antiguo, CCHS-CSIC] 

Artículos

El estilo decorativo en las primeras producciones cerámicas en el valle del río Vinalopó (Alicante).

Silvia Martínez Amorós.

Límites históricos del Ateísmo: increencia en la Grecia Antigua.

Ramón Soneira Martínez. .33

Dynamics of Power: an Architectural Reading of the Concentration of Power (Ullastret, 4th-3rd Century BC).

David Jesús Cebrián Martínez.

La mujer como exemplum. Subversión, desafío y resistencia en Valerio Máximo.

Lidia González Estrada.

The narrative framing of violence in teaching resources about the Spanish Conquest of America.

Ángela Bermúdez Vélez y Diego Argumero Martínez.

Modelos de conciencia histórica en el alumnado de Educación Secundaria: tradición, simbología y contextualización en torno a los restos del franquismo.

Diego Miguel-Revilla y María Sánchez Agustí.

La importancia de la contextualización curricular en la enseñanza de la Historia en México.

Enrique Bautista Rojas.

Experiencia didáctica para la enseñanza de la historia contemporánea a través de las fuentes en Educación Superior.

Nayra Llonch-Molina y Verónica Parisi-Moreno 161

\section{Reseñas}

Prados, F., Jiménez, H., Martínez, J.J. (Eds.) (2017). Menorca entre fenicis i púnics / Menorca entre fenicios y púnicos. Murcia: Centro de Estudios del Próximo Oriente y la Antigüedad Tardía de la Universidad de Murcia. 320 págs.

Pete Missingham

Bravo Bosch, M. J. (2017). Mujeres y símbolos en la Roma Republicana. Análisis jurídico-histórico de Lucrecia y Cornelia. Madrid: Dykinson. 333 págs.

Borja Méndez Santiago.

Karp, M. (2016). This Vast Southern Empire: Slaveholders at the Helm of American Foreign Policy. Cambridge: Harvard University Press. 360 pages.

Kevin Caprice.

Livi-Bacci, Massimo (2012). A Short History of Migration. Cambridge: Polity Press. 157 pages.

Alejandro Salamanca Rodríguez. 189

Normas de publicación/Publishing rules 



\title{
La importancia de la contextualización curricular en la enseñanza de la Historia en México
}

\author{
The Importance of the Curricular Contextualization in History Teaching in Mexico
}

\author{
Bautista Rojas, Enrique ${ }^{1}$ \\ Asesor pedagógico de Educación básica (México)
}

Recibido: 07/06/2017

Aceptado: 06/12/2017

Para citar este artículo: Bautista Rojas, Enrique (2018). La importancia de la contextualización curricular en la enseñanza de la Historia en México. Panta Rei. Revista Digital de Ciencia y Didáctica de la Historia, 143-160.

ISSNe: 2386-8864

DOI: $10.6018 /$ pantarei/2018/7

\section{Resumen}

El propósito de este trabajo es analizar la importancia de la contextualización curricular en la enseñanza de la historia en la escuela secundaria en México. Esto implica la generación de experiencias educativas que favorezcan el desarrollo del pensamiento histórico a partir de la construcción de aprendizajes significativos y situados que consideren las características de los estudiantes y su entorno. Se discute tomando referentes teóricos derivados del socioconstructivismo para criticar la forma en que tradicionalmente se ha enseñado la historia en este nivel educativo, lo que ha dado por resultado procesos poco relevantes en la vida escolar y cotidiana de las y los jóvenes. Al abordar este tema, se busca brindar pautas de reflexión y puntos para guiar el trabajo de los docentes y favorecer su compromiso hacia la formación de futuros ciudadanos críticos, informados y comprometidos con su sociedad.

\section{Palabras clave}

Enseñanza de la historia, evaluación formativa, métodos de enseñanza, procesos cognitivos, profesores.

\begin{abstract}
The intention of this paper is to analyze the importance of curricular contextualization in the history teaching in Mexican junior high school. This implies the generation of educational experiences that support the development of historical thinking through the construction of significant and situated learnings that consider the characteristics of students and their environment. The discussion takes references derived from the social constructivist theory and criticizes the traditional teaching of history in this educational level. This teaching method has resulted in unimportant processes in the school and daily life of young people. The work seeks to provide reflection guidelines and points to guide the teaching practice and promote its commitment to the formation of future critical, informed and committed citizens to their society.
\end{abstract}

1 Para contactar con el autor: Enrique Bautista Rojas. Investigador independiente y Asesor pedagógico de Educación básica (México). kique_pedagogo.unam@hotmail.com. 


\section{Keywords}

History instruction, formative evaluation, teaching methods, cognitive processes, teachers.

\section{El verdadero aprendizaje debe situarse en una cultura de necesidades y prácticas que ofrece un} contexto, una estructura y una motivación a los conocimientos y habilidades aprendidos

(Perkins, 1995, p. 74).

\section{Introducción}

En ocasiones cuando se habla de que el estudiante es el centro de los procesos de enseñanza y aprendizaje, se olvida que no es un ser en abstracto, pues existe dentro de un contexto en el que vive y en el cual ha construido sus conocimientos, tanto en el ámbito formal como informal. Se observa la separación del contexto y las prácticas educativas generándose de este modo ambientes de aprendizaje alejados de la realidad. En algunos casos se reproducen las clases como si fueran secuencias ya hechas que no requieren ninguna variación, dejando de lado la diversidad y las diferencias que existen en el aula².

En consecuencia, el acercamiento que tienen los alumnos a la historia es a partir de actividades tradicionales como el copiado, la memorización de fechas y nombres, y la elaboración de resúmenes. Esto se traduce en aprendizajes que carecen de significado, que son poco aplicables en la vida escolar, y que no pueden transferirse y articularse entre sí y con la vida cotidiana de los alumnos (Díaz-Barriga, 2003; Donovan, Bransford y Pellegrino, 1999).

A pesar de que en algunos casos se han superado prácticas tradicionales donde el "gis y el pizarrón" eran los elementos básicos para la clase y se ha introducido el uso de imágenes, mapas, líneas del tiempo u otros mediante el uso de las tecnologías de la información y la comunicación (TIC) - como vídeos, interactivos o audios -, en distintas propuestas la descontextualización de la enseñanza sigue presente, ya que no se incluyen aspectos de la vida cotidiana de los alumnos que permitan la comprensión de los procesos y acontecimientos históricos. Aunque los medios se han actualizado y se busca que sean atractivos, en la práctica terminan siendo sesiones tradicionales disfrazadas de innovadoras.

Con base en lo expuesto, en el presente artículo se analiza la importancia de las adaptaciones o ajustes curriculares dentro de la asignatura de Historia teniendo en cuenta la contextualización que requieren los procesos de enseñanza y aprendizaje para generar ambientes y prácticas educativas que favorezcan el desarrollo de conocimientos, habilidades y valores en los alumnos, a partir de un punto de vista formativo de la asignatura. Se presentan elementos de discusión en relación a los momentos de planificación y evaluación para la generación de un conocimiento situado que motive la construcción compartida de conocimientos.

Para el presente caso, se toma como referente el nivel de secundaria, el cual forma parte del trayecto formativo correspondiente a la Educación obligatoria en México. Como características de este nivel es de mencionar que los docentes que imparten la asignatura en cuestión son en su mayoría de especialistas de Historia o carreras afines. En muchos casos se trata de profesionales que carecen de una formación específica para la enseñanza de la Historia en las aulas, lo que

2 Hay que tener en cuenta que la diversidad en el aula debe entenderse a partir de las características de los alumnos en conjunto, de tal modo que todas las aulas tienen diferentes elementos que confluyen durante el tránsito en la escuela. Anijovich, Malbergier y Sigal (2007, p. 23), argumentan que se deben comprender como "aulas heterogéneas" que "no sólo apunta a tomar conciencia de las variaciones existentes en una población de alumnos en lo que respecta a su inteligencia y sus logros de aprendizaje, sino que incluye diferencias relevantes a la hora de abordar la enseñanza: origen, etnia, cultura, lengua, situación socioeconómica, características personales, estilos de aprendizaje, inteligencias, inclinaciones, necesidades, deseos, capacidades, dificultades, entre otras". 
ha generado prácticas tradicionales y poco acordes con las características y necesidades de sus estudiantes.

Vinculado a estas razones, se considera como un nivel importante dentro del trayecto formativo de los estudiantes (de entre 12 y 15 años de edad), como parte de su incorporación a la vida en sociedad. Teniendo en cuenta la potencialidad que tiene la Historia en el desarrollo de capacidades sociales y personales, es menester la transformación de la forma en que se aprende ésta en las aulas. Señalan Seixas y Colyer (2012) que al final de la educación secundaria los estudiantes deben tener las herramientas y capacidades necesarias para poder participar en sociedad y contribuir al debate democrático; en ello la historia puede desempeñar un papel clave. De ahí que se considere necesario brindar elementos a los docentes a fin de crear oportunidades de aprendizaje que resulten significativas para los estudiantes.

Es de destacar que los conceptos de adaptaciones o ajustes en este trabajo aluden a la contextualización como forma de acercar el currículo a la vida cotidiana y a los referentes de los alumnos. Esta anotación se hace necesaria para evitar la ambigüedad con el término "adecuación curricular", cuyo empleo hace referencia a las alternativas que se proponen para los estudiantes que presentan alguna necesidad educativa especial y/o discapacidad, y que responden a un enfoque de la educación inclusiva, cuyo tratamiento no se hará en el presente documento.

En un primer momento se presentan aspectos relacionados con la contextualización curricular a partir de una postura socioconstructivista del aprendizaje y de la enseñanza de la historia, con un sentido formativo y para la vida. Posteriormente se buscan brindar algunos planteamientos derivados de la consulta bibliográfica de distintos trabajos con la intención de orientar y brindar pautas para la construcción de experiencias contextualizadas en la escuela como parte de la didáctica de la historia, haciendo énfasis en lo relativo a las estrategias de enseñanza y aprendizaje, así como de la evaluación del pensamiento histórico. Es propicio señalar que, aunque la contextualización curricular no es un concepto nuevo, pues ya desde la década de los setenta y ochenta se ha tenido en consideración (Gillespie, 2002), es necesario retomar los planteamientos que propone, toda vez que continúan siendo vigentes y aplicables, teniendo además en cuenta la existencia de prácticas tradicionales en las aulas.

\section{La contextualización de la enseñanza y el aprendizaje}

Hablar de los procesos de enseñanza y aprendizaje implica tener en consideración diferentes elementos que tienen influencia sobre ellos. Contrario a lo que en ocasiones se piensa, la escuela no es un espacio ajeno a lo que ocurre a su alrededor; docentes, alumnos y prácticas educativas se ven mediadas por el contexto en que se insertan. Resulta poco apropiado pensar que el conocimiento es ajeno a lo que ocurre en las situaciones de la vida cotidiana pues en realidad es de ésta de donde se ha derivado, como parte de las explicaciones que las personas han creado para comprender el mundo social y cultural a través del tiempo.

Desde una postura constructivista, se propone que el aprendizaje se adquiere a partir de procesos activos donde los alumnos transforman sus esquemas e ideas previas en un proceso de asimilación y acomodación donde constantemente se construyen conocimientos (Piaget, 1991). Significa que las personas cuentan con referentes previos que ha desarrollado antes de entrar a la educación formal o que construyen de forma progresiva a través de su paso por el espacio escolarizado. Y es mediante las actividades propuestas en las aulas que se descubren y amplían los saberes, y se desechan ideas que poco a poco se van considerando como no ciertas o prejuiciosas.

Si la tarea de la escuela es acercar a los jóvenes a nuevos saberes, entonces ¿por qué es importante tener en cuenta los conocimientos previos de los alumnos, es decir, ideas que ya poseen y que además presentan errores y distorsiones? (Aisenberg, 1994). Desde pequeñas - incluso antes de ingresar a la educación formal -, las personas buscan explicarse sucesos que ocurren a su alrededor, tanto en aspectos naturales como sociales. En el caso de la Historia, sus primeros acercamientos se dan a partir de experiencias familiares y comunitarias y a través del contacto con 
películas, medios de comunicación, eventos culturales (Taylor y Young, 2003) y en algunos casos por visitas a museos o sitios históricos con fines lúdicos o turísticos.

Comienzan a generar representaciones del tiempo y del lugar en el que les ha tocado vivir mediante códigos o formas de expresar su realidad. Aunque estas explicaciones no sean las que se buscan promover desde la escuela, sean incompletas o erróneas, es necesario que se consideren como elementos del proceso de aprendizaje, ya que constituyen los esquemas iniciales sobre los cuales es posible emprender el trabajo (Bravo, 2009).

Cuando en los procesos de enseñanza y aprendizaje interactúan estas experiencias anteriores y los conocimientos previos e informales de los estudiantes con aspectos concretos de la Historia, es posible generar oportunidades donde, de manera gradual, se incorporan y desarrollan esquemas cognitivos mediante la interpretación y la reflexión (Dewey, 2010). Desde la perspectiva ausubeliana, este proceso de vinculación se da con el establecimiento de andamiajes (Ausubel, Novak y Hanesian, 2009) o anclajes entre los aprendizajes que se espera logren los alumnos y los elementos previos con los que cuentan. En contraste, cuando no ocurre esta vinculación y, por el contrario, se busca erradicar en lo posible los saberes informales y previos de los estudiantes por considerar que no tienen valor alguno, se producen procesos que poco favorecen la construcción de esquemas, reduciéndose así a un aprendizaje de la historia por memorización (Taylor y Young, 2003).

La postura socioconstructivista (Vygotsky, 1979) propone que el contexto y la influencia de la cultura son importantes en el aprendizaje. Es a partir de las interacciones sociales que se dan por medio del lenguaje que se desarrollan y estimulan distintos procesos cognitivos. La modalidad de la persona más el entorno (Perkins, 1995) plantea que las personas no construyen de forma aislada el conocimiento, sino que es mediante las interacciones sociales y con el entorno que adquieren datos e información que les permiten construir sus visiones del mundo.

De ahí la relevancia de que lo que ocurre en las aulas se dé de forma activa y participativa, pues en la medida en que sucedan así, las estudiantes lograrán alcanzar niveles de comprensión conjunta cada vez más complejos. Una escuela inteligente (Perkins, 1995) debe poner énfasis en la actividad compartida, más que en la tendencia hacia la individualización. No significa dejar de lado la consideración sobre las particularidades de cada estudiante, sino reconocer el potencial que se deriva del trabajo en conjunto cuando este se da en un contexto donde se recuperan los saberes colectivos.

Hay que destacar que el concepto de contextualización tiene diferentes significados, por lo que en esta propuesta se entenderá como:

Un proceso a través del cual, las propuestas curriculares se ajustan a los parámetros particulares de los diversos entornos, instituciones y colectivos donde se aplicarán. En dicho proceso, la lógica de lo general, lo estandarizado, lo prescriptivo se contrapone a la lógica de lo local, lo situacional, lo adaptativo. Se trata de una visión de la educación y de la función de las escuelas contraria a la homogeneización y respetuosa con la diversidad (Zabalza, 2012, p. 6).

Estos ajustes implican el uso de estrategias desafiantes y recursos de calidad que permitan la vinculación y comprensión de los aprendizajes, los contenidos académicos y las aplicaciones concretas en un contexto específico y de interés para los estudiantes (Mazzeo, Rab y Alssid, 2003; Rivet y Krajcik, 2008). De esta caracterización se deriva también que, si bien en México existe un currículo nacional obligatorio donde se enmarcan contenidos que resultan claves en el aprendizaje, es necesario que el docente haga las adecuaciones que considere pertinentes para llevar a cabo los procesos de enseñanza, teniendo en cuenta las características de sus alumnos, del entorno y las posibilidades que éste le brinda.

Con base en el conocimiento que tienen los docentes acerca de sus estudiantes, es posible que comprendan mejor sus necesidades e intereses, y retomen estos elementos para adaptar la propuesta nacional a la cotidianeidad y realidad en que se ubica la escuela (Squire, Makinster, 
Barnett, Luehmann y Barab, 2003), lo cual desde el diseño curricular en ciertos momentos no es posible lograr, sobre todo si se tiene en cuenta la diversidad de contextos existentes en el país. La propuesta implica reconocer las experiencias y contextos de los alumnos como elementos para el aprendizaje de la historia, y donde continúen siendo parte central de los procesos, pero ya no como seres ajenos a las circunstancias de su tiempo y espacio, sino como sujetos integrales que en la escuela están con todo de sí.

Impulsar la idea de que el aprendizaje debe ser contextualizado, cercano y vinculado con la realidad de los jóvenes tiene como intención la generación de experiencias significativas que los lleven a desarrollar conocimientos, habilidades, valores y actitudes enfocados a una historia que coadyuve a "aprender a aprender" y "aprender a convivir". Implica poner en juego las distintas habilidades y los sentidos en interacción con el medio para construir conocimientos (Romero, 2010). Resumir la tarea del docente y de la escuela a la mera transmisión de los conocimientos planteados en el currículo deja de lado elementos claves en la formación de los alumnos pues la escuela, además de ser un espacio donde se llevan a cabo los procesos de enseñanza y aprendizaje, es un lugar para desarrollar habilidades sociales para la vida a partir de la comprensión de los demás y del sí mismo.

El papel de los docentes es relevante pues a través de la interacción y la experiencia compartida, los estudiantes acceden a niveles que difícilmente lograrían alcanzar de estar solos (Domínguez, 1986; Vygotsky, 1979). Fundamental es que generen experiencias como recursos para el aprendizaje (Dewey, 2010) y que se logre la transformación del conocimiento a partir de la experiencia (Kolb, 1984). Una de las principales críticas al sistema escolar tradicional es lo estático de sus formas de enseñanza que poco favorecen la construcción de esquemas del pensamiento cada vez más complejos; en contraste, el énfasis deberá estar en la indagación, la experimentación y las experiencias como elementos significativos para el desarrollo de los conocimientos.

Lo contrario ocurre cuando las prácticas tradicionales provocan que en ocasiones la asignatura sea vista por los estudiantes como aburrida, con poca relevancia para su vida cotidiana y que consiste básicamente en la memorización de fechas, nombres de personajes y conflictos bélicos (esto derivado igualmente de los enfoques tradicionales que enfatizan lo político sobre lo social y cultural). En niveles como la secundaria, los enfoques de enseñanza adoptados por los docentes parecen continuar mostrando a la historia como un conjunto de saberes cerrados y ajenos a la vida cotidiana de las personas, y se justifican como necesarios de aprender por formar parte del bagaje cultural que todos deben saber (Gómez y Rodríguez, 2014), aunque sin tener claros por qué y para qué.

Esto genera, entre otras consecuencias, que los jóvenes se sientan poco motivados para acercarse a la historia, pierdan el interés y, por tanto, tengan un bajo rendimiento escolar ${ }^{3}$. Aunado a ello, el desarrollo de una actitud crítica y empática con lo que ocurre fuera de la escuela en el ámbito social, se ve poco favorecido, limitando la generación de una conciencia histórica y de una formación ciudadana comprometida. En dichas circunstancias, es posible cuestionar si realmente es factible que los estudiantes alcancen niveles complejos de conocimientos y de conciencia social -que les impulse entender su contexto y colaborar en él- a partir de las prácticas tradicionales de enseñanza de la historia (Gómez, Miralles y Molina, 2015).

Considerando las características actuales de la educación, la enseñanza de la historia en México centrada en la transmisión de conocimientos de forma vertical, como para llenar "jarras

3 Santacana, Martínez, Llonch y López (2016) señalan que uno de los retos a los que se enfrenta la escuela en la actualidad es el abandono escolar, el cual se debe a diversas situaciones, siendo una de ellas la poca capacidad de retención de los centros educativos debido a la falta de significado que tiene lo que se enseña en las aulas para los estudiantes. En el contexto de lo dicho hasta el momento, se justifica la importancia de vincular la experiencia educativa con la vida cotidiana de los estudiantes. De este modo, de acuerdo con Perin (2011) se lograrán mayores tasas de retención escolar, acceso a más grados de educación obligatoria y un mayor impacto en la trayectoria escolar de los estudiantes. 
vacías", donde existe un relato único, una interpretación universal y la presencia de ciertos protagonistas, resulta difícilmente justificable y pertinente. La historia debe virar al desarrollo de una postura y visión crítica del presente en los estudiantes (Prats y Santacana, 2011).

Se propone pensar a la historia desde un punto de vista formativo que implique centrar la atención en los estudiantes y al desarrollo de conocimientos, habilidades, valores y actitudes que les permitan la comprensión del mundo que les tocó vivir, tomando conciencia de la forma en que el pasado, presente y futuro están íntimamente relacionados, y actuando en la resolución de problemas de manera crítica e informada, en la medida de sus posibilidades (Arista, 2011). La función de la historia debe estar vinculada con el aprender a pensar históricamente y de manera crítica, lo cual requiere desarrollar elementos para relacionar el conocimiento histórico con las acciones sociales (Quintero, 2016).

La intención es que los jóvenes aprendan a pensar históricamente, mirando lo que ocurre a su alrededor para comprender que los procesos y acontecimientos que ocurrieron en el pasado, tienen vínculo con el presente, así como con el futuro. Esto mediante el desarrollo de la conciencia histórica, entendida como la capacidad para interrelacionar fenómenos del pasado y del presente, la convicción de que las sociedades están sujetas a transformaciones (no son estáticas) y que éstas constituyen el presente; asimismo, que cada individuo tiene un papel en esas transformaciones, por lo que el pasado es parte de cada persona (Sáiz, 2013).

Al comprender su papel como parte de la sociedad, tanto nacional como mundial, se busca que se asuman como participes activos y que, en la medida de sus posibilidades, pueden participar de manera crítica e informada en la resolución de problemas de su contexto. El análisis de la relevancia histórica (Seixas y Morton, 2013) de ciertos procesos y acontecimientos históricos puede contribuir a que los estudiantes identifiquen la importancia de estudiar el pasado al identificar que de ellos han surgido cambios que tienen consecuencias para muchas personas, durante un largo periodo de tiempo o con influencia en la vida contemporánea.

El aprendizaje de la historia debe permitir la reflexión acerca de estas relaciones, contextualizar la realidad e interesarse por los problemas del presente con una postura crítica e informada. Este es un reto para la historia, de forma tal que se logre una verdadera interacción entre la realidad y la escuela (Perafán, 2013) pues de cierto modo, no son asuntos disimiles o ajenas la una de la otra. Sustancial es estrechar la conexión con el contexto a partir del análisis de la sociedad y sus desafíos, y de poder transferir y aplicar a ellos los aprendizajes desarrollados de forma activa (Gillespie, 2002).

Bajo la propuesta de contextualización curricular, "la enseñanza de la historia debe enfocarse en el estudio del pasado como forma de comprender el presente, en vez de una mera transmisión de la herencia cultural de una sociedad" (Díaz-Barriga, 2005, p. 5). Al hacer esto, los procesos educativos, el entorno y sus elementos juegan un papel relevante como recursos que motivan las relaciones entre lo que viven los estudiantes y los contenidos que forman parte del currículo, logrando hacer contrastes, analizar realidades, problematizar situaciones, buscar información, participar y proponer soluciones informadas. Esto considerando lo sustancial que es que los jóvenes cambien su rol de espectadores y se involucren como participantes (DeLott, Hope y Karandjeff, 2009).

\section{Hacia la generación de experiencias de aprendizaje contextualizadas}

A partir de la mediación que ocurre entre profesores y alumnos se construyen conocimientos que parten de diferentes procesos que implican no sólo conceptos, sino también habilidades, valores y actitudes que se articulan unos con otros. Estas prácticas educativas se ven enriquecidas cuando toman en cuenta lo que ocurre en el contexto de quienes aprenden y se establece vínculos que favorecen el aprendizaje de forma significativa.

Hay que destacar que no basta la simple asociación entre uno y otro, sino que es necesaria la interacción y mediación como parte de los procesos de enseñanza y aprendizaje. Si no se logra propiciar esto, aunque el alumno tenga los esquemas previos necesarios, no logrará establecer la 
vinculación significativa. Depende en gran medida de que las ideas, hechos o experiencias que posee el alumno y que forman parte de su vida cotidiana sean consideradas dentro de los procesos, ya que, si no se favorece esto, se podría pensar que lo que se está estudiando es algo muy lejano, sin ligaduras con el presente o difícil de comprender, generándose así bloqueos cognitivos y falta de motivación para aprender.

Es necesaria la motivación que puede generar el docente, pero también la disposición que quien aprende tenga, pues cuando no hay apertura para expresarse por el temor al equívoco o por considerar que no es apropiado lo que saben, se generan ambientes de escasa participación y que poco favorecen las experiencias educativas. Corresponde al docente la generación de ambientes propicios donde las actividades representen desafíos o tareas complejas que llevan a la reflexión y a establecer vínculos entre la escuela y la comunidad. De esta forma, se logrará que el alumno se sienta atraído para participar en las tareas al percibirlas como útiles (Perin, 2011) y cognitivamente desafiantes.

La disposición para aprender y la presentación de materiales que resulten potencialmente significativos (Rodríguez, 2004) son también condiciones fundamentales para que se dé el aprendizaje. Sin embargo, por sí solo el material que pudiera usarse, por más atractivo que éste sea, no generará verdaderas experiencias, sino a partir de la interacción que haya entre los miembros y los recursos empleados. El material debe tener un significado lógico y, a la vez, que los sujetos cuenten con las ideas previas que les permitan realizar los anclajes necesarios, de lo contrario, no tendrán importancia y se olvidarán pronto, pues únicamente se memorizará por un periodo breve ante la falta de un sentido claro.

La generación de aprendizajes contextualizados también implica una toma de conciencia sobre el trabajo docente y el reconocimiento de las dificultades que se tienen. Este es un punto sensible pero necesario si se quiere transformar la práctica en aras de un trabajo más comprometido, no sólo con su profesión, sino con la formación de sus alumnos y su correspondiente impacto social. También resulta necesario cambiar las concepciones de los docentes, quienes deberán cuestionar las tradiciones y prácticas escolares heredadas y asumidas como verdaderas, y en contraste abonar a la transformación necesaria en la enseñanza de la historia (Monteagudo, Molina y Miralles, 2015).

\subsection{Las estrategias de enseñanza y aprendizaje}

Siguiendo el argumento de Pagés (2004, p. 157) "no basta con saber lo que debe enseñarse, es necesario saber muchas otras cosas". Esto destaca que el conocimiento histórico del docente no será suficiente dentro de los procesos formativos en el aula, si se reduce al saber mismo de forma disciplinar. Es imperioso establecer comunicación eficiente y motivación a partir de la forma en que se llevan a cabo las sesiones; es necesario articular el saber disciplinario con la visión didáctica de acuerdo con las intenciones educativas (Vázquez, 2013). Esto es un desafío para los docentes de secundaria, quienes -aunque son especialistas en el área y cuentan con amplios conocimientos históricos- deben tener presente en la planificación de sus actividades el contexto en que se desarrolla su práctica y la forma en que acercarán a los alumnos a los procesos y acontecimientos históricos.

Esta reflexión es necesaria al momento de prever la forma en que se enseñará historia en el aula. Muchos docentes se enfrentan a la falta de recursos y estrategias didácticas que puedan favorecer aprendizajes significativos en sus estudiantes. Aunque cuentan con la formación específica y poseen el conocimiento histórico (y algunos más cuentan con años de experiencia frente a grupo), no logran desarrollar situaciones que movilicen las capacidades de los jóvenes.

Se suma la dificultad para poder contextualizar los contenidos, pues sus nociones acerca de didáctica de la historia y cómo llevarla a cabo en las aulas son limitadas. Planificar desde la contextualización curricular implica que los docentes esbocen con base en la información obtenida a partir de sus observaciones y el acercamiento a los conocimientos previos de sus alumnos (Gillespie, 2002) para diseñar situaciones que combinen la vida cotidiana con los conocimientos 
históricos señalados en los programas de estudio. Las estrategias deberán superar prácticas como el copiado o privilegiar la memorización, para acercar a los alumnos a situaciones que les permitan investigar, explorar, buscar, justificar, reflexionar, comunicar lo que saben y compartir con los demás, motivando su curiosidad por explicar aspectos relacionados con los procesos y acontecimientos del pasado, favoreciendo su vinculación con el presente y ejemplificando o proponiendo algunas ideas.

Ciertas propuestas intentan hacer símiles de las prácticas o actividades que desarrollan los expertos y que los jóvenes piensen o actúen como si fueran historiadores. Sin embargo, éstas no necesariamente generan aprendizaje significativo ya que no basta con extrapolar estas situaciones al aula, pues el empleo de las fuentes históricas dista mucho de cómo lo hacen los especialistas (DíazBarriga, 2003). Hay que considerar que el conocimiento del experto no es el mismo que poseen los alumnos de secundaria (ni de ningún otro nivel de Educación básica), no sólo en cuanto a cantidad o profundidad, sino también la calidad del mismo (Díaz-Barriga, 2003). Comenta Domínguez (1989, pp. 49-50) que "las fuentes no nos informan de manera directa y acabada, sino sólo en función de lo que el historiador decida interrogarles, sólo en ese momento se convierten en las pruebas sobre las que apoya su argumentación".

Esta crítica es apoyada por Wineburg, Smith y Breakstone (2012) quienes comentan acerca de las alternativas basadas de manera predominante en las fuentes donde se pide a los alumnos la lectura de documentos, la formulación de hipótesis, la elaboración de ensayos o artículos, con coherencia y claridad en el límite de una hora destinada en el mapa curricular para la asignatura de Historia. Los autores critican la falta de claridad sobre aquello que se busca evaluar con actividades de este tipo, pues más que centrarse en el desarrollo del pensamiento histórico, someten a los alumnos a procesos de tensión por condiciones de tiempo y cantidad de documentos que requerirán para sustentar sus argumentos, "así como lo hacen los historiadores".

Además de poco pertinente, es insuficiente, pues a la par de enseñar el método de la investigación histórica, es necesario el desarrollo de capacidades para, entre otras cosas, explicar el pasado, cómo evoluciona y cómo se transforma la vida de los hombres en el tiempo (Domínguez, 1986). La intervención docente es necesaria en este trabajo con las fuentes, pues resultará poco viable pensar que los estudiantes por sí solos pueden acceder a niveles de construcción histórica sin la orientación adecuada, aunque ya hayan pasado previamente por los grados de la educación primaria. La intervención deberá continuar de manera permanente coadyuvando al desarrollo de capacidades cada vez más complejas y en ámbitos de análisis más amplios.

Si bien esta observación señala la forma en que se emplean las fuentes de una forma poco contextualizada para los alumnos, no por ello se niega la importancia que éstas tienen en el estudio de la historia. Sin embargo, hay que pensar más en el sentido formativo que en la idea de pretender formar "pequeños historiadores". El propósito es acercar a los alumnos a las huellas del pasado de una forma didáctica, más que disciplinar propiamente, para que desarrollen el pensamiento histórico, valoren el pasado y lo empleen para comprender el mundo y describir las sociedades del presente (Gómez, Ortuño y Molina, 2014; Gómez y Rodríguez, 2014; Santacana, 2005).

Retomando el punto, el docente de secundaria se enfrenta al reto de pensar en estrategias para y con los alumnos, ya que, al involucrarlos en los contenidos, pero también en la forma en que se enseña y aprende historia, estos se entusiasman, se favorece su participación y se impacta en sus aprendizajes (Kirk, 2012). Teniendo en cuenta los intereses y lo que han identificado durante las sesiones, los docentes se pueden percatar de las posibilidades que tienen sus estudiantes, las áreas que necesitan fortalecer y prever las formas en que el trabajo resulte atractivo, relevante y cercano a ellos. Este desafío también se traduce en romper con los esquemas que han sido formados en los alumnos de secundaria durante su trayecto escolar a partir de actividades tradicionales que han generado percepciones y resistencias hacia la historia en grados previos.

Para quienes han tenido la oportunidad de estar en un aula de educación secundaria, seguramente resultará familiar la pregunta "¿y esto para qué me va a servir?". El planteamiento puede tener dos intenciones: por un lado, como una forma de curiosidad natural por conocer la forma en que ese conocimiento se relaciona con lo que ocurre a su alrededor y cómo podrán 
movilizarlo en distintos contextos; pero, por otro lado, expresa la desilusión sincera ante las clases de Historia que no tienen significado ni implicación con lo que ven en su vida cotidiana. Esto último sobre todo para los alumnos que en grados escolares anteriores no han logrado enlazar aquello que se les ha enseñado con su realidad; es decir, no encuentran conexiones entre eso que se pretende que aprendan y su cotidianeidad (Perafán, 2013). Los jóvenes buscan así reconocer el significado de aquello que se pretende que aprendan y por qué es relevante que lo conozcan (Kenea, 2014).

En contraste con la anterior cuestión, algunas de las estrategias que los docentes de secundaria pueden emplear para generar estos ambientes a partir de la contextualización son el aprendizaje basado en problemas (ABP), los análisis de casos, la elaboración de proyectos, las simulaciones o juegos de roles, los debates, entre otros, que promueven el desarrollo de capacidades complejas cimentadas en el trabajo que se ha hecho en la educación primaria. Cuando a los estudiantes se les pone en situaciones donde analizan problemáticas y se les estimula a proponer alternativas o explicaciones a dichos problemas se favorece que adquieran aprendizajes, los movilicen y los vayan vinculado progresivamente con su vida (Canals, 2013).

En los estudios de caso, los alumnos se ven inmersos en investigaciones donde analizan una situación, definen problemáticas, buscan información en diversas fuentes, la contrastan y la socializan con otros, exponiendo sus puntos de vista (Gómez y Rodríguez, 2014). Para favorecer la vinculación con el presente, se pueden partir de problemáticas o asuntos que sean cercarnos o de preocupación para los jóvenes y cuya comprensión impliquen la investigación de acontecimientos o procesos del pasado. Otras estrategias, que recientemente se han impulsado, y con atractivo potencial para los estudiantes -dada la cercanía que representa para algunos de ellos- puede ser el uso de diversos géneros musicales como el rap (Egea, Arias y Clares, 2017) que les permiten acercarse a la historia y poder comunicar hallazgos de manera organizada, fluida y congruente.

El desarrollo de la empatía es un aspecto que no debe quedar de lado como parte del desarrollo de la conciencia histórica. Los ejercicios de proyección, reconstrucciones imaginarias, ejercicios de contrariedad, contrastes entre el pasado y el presente permiten a los estudiantes acercarse al pasado, demandando que dejan de lado su mirada actual sobre los acontecimientos para buscar tomar la perspectiva, motivaciones, ideas y acciones de las personas del pasado en su contexto histórico (Domínguez, 1986; Seixas y Morton, 2013).

Estas estrategias tienen la ventaja de presentar situaciones que vinculan lo que sabe el alumno con los procesos y acontecimientos históricos, buscan la recuperación de los conocimientos previos, la motivación hacía la búsqueda de respuestas o soluciones ante planteamientos, el acercamiento a partir de la consulta y manejo de diferentes recursos, el trabajo en equipo, el compartir ideas y argumentos, así como generar explicaciones y reflexiones en torno a lo que se ha estudiado. Hay que recordar que "cuando el alumnado se enfrenta al desafío de responder a un amplio abanico de situaciones reales, se consolida en él un conocimiento significativo, contextualizado, trasferible y funcional y se fomenta su capacidad de aplicar lo aprendido" (Romero, 2010, p. 90).

El acercamiento, por ejemplo, puede iniciar con preguntas motivantes o que resulten atractivas a los alumnos, considerando lo que ellos pueden saber al respecto y buscando vincularlo con su contexto y el presente. Las preguntas cerradas o sin una intención clara, por ejemplo "¿Qué saben acerca de la Independencia de México?", probablemente no permitan que los alumnos expresen lo que saben, pues la forma en que se hace el planteamiento demuestra que se busca una respuesta concreta o vaga, como "nada" o "no sé". Se debe favorecer la formulación de preguntas que cuestionen la información desde diferentes aristas. Los planteamientos tendrán que ser muy pensados, teniendo en cuenta la forma en que se puede dar ese acercamiento a los alumnos y que considere los elementos del contexto. Asimismo, la forma en que se lleven a cabo las actividades deberá motivar el desarrollo de los conocimientos, valores y actitudes, y no enfocarse de manera exclusiva a alguno de ellos.

Continuando con el ejemplo anterior, el tema de la "Independencia de México" está inmerso en la vida cotidiana de los jóvenes desde tempranas edades, pues no sólo constituye una fecha de conmemoración cívica nacional, sino también de celebración. Así, en fechas cercanas al 15 y 
16 de septiembre, las calles y casas se llenan de los colores de la bandera (verde, blanco y rojo) y las imágenes de los participantes del movimiento independentista se observan en muchos lados. En las escuelas -sobre todo de educación preescolar y primaria- es común que se represente el pasaje del "Grito de Dolores" que marcó el inicio del movimiento y se imiten los "iviva!" y el toque de campana. Asimismo, en la noche del 15 de septiembre tiene lugar la ceremonia de "El grito" desde el Palacio Nacional (ubicado en la Plaza Mayor o Zócalo de la Ciudad de México) donde el presidente realiza un ejercicio similar, el cual es televisado en cadena nacional, y es replicado en plazas cívicas a nivel estatal y municipal por gobernadores y alcaldes ante la presencia de muchas personas que se reúnen esa noche.

Aunque de manera informal su acercamiento al movimiento histórico se ha dado desde asuntos de la vida social y cotidiana, representa un ejemplo claro de la forma en que el aprendizaje que se va formando afuera de la escuela puede retomarse para generar experiencias situadas. Formalmente, durante los grados de primaria, los alumnos se acercan a la revisión de contenidos vinculados con el hecho histórico, el reconocimiento de algunos personajes y la generación de explicaciones y análisis iniciales como parte de las clases.

Dichas actividades forman parte de los esquemas de los jóvenes, quienes de una manera u otra comienzan a reconocer algunos conceptos o frases vinculadas, identifican a ciertos personajes, son participes de la situación que se conmemora y empiezan a comprender la importancia del acontecimiento. Igualmente, es posible recuperar ideas en los jóvenes acerca de distintos conceptos o percepciones que se han formado y buscar trasladarlos a un determinado proceso histórico a estudiar; “¿Qué creen que es una guerra?”, “¿Por qué creen que las personas se enfrentan en guerras?", son preguntas que contrastan para la movilización de ideas previas en comparación con un planteamiento del tipo “¿Qué es la guerra de Independencia?”.

En algunos casos ocurre que la recuperación de los conocimientos previos se limita a un momento formal de la clase donde a través de una "lluvia de ideas" o brainstorming los estudiantes expresan sus ideas, las cuales son escuchadas por el docente - y anotadas en el pizarrón en el mejor de los casos - sin que suceda nada más con ellas. Esta estrategia muy recurrente para conocer qué saben los alumnos sobre algún tema enfoca su atención a la presentación y recuerdo de datos, pero no necesariamente al establecimiento de conexiones entre ellos (Blumenfeld, Marx, Patrick, Krajcik y Soloway, 1997).

Por el contrario, dichas ideas, además de recuperarse, hay que movilizarlas y ampliarlas a través de las actividades buscando así progresiones cada vez más complejas y al finalizar una estrategia, por ejemplo, la comparación de lo externado al inicio con la concepción final puede dar cuenta de los avances logrados o las dificultades que hay que considerar para continuar trabajando.

Asimismo es posible aprovechar el acercamiento interdisciplinar a partir de las actividades favoreciendo capacidades como la integración, contraste y síntesis, a la vez que se refuerzan las distintas asignaturas, por ejemplo, desarrollando las habilidades de expresión oral y escrita, favoreciendo el análisis iconográfico mediante la consideración de los diversos elementos de una imagen, interpretando gráficas o datos numéricos que expresan información sobre algún acontecimiento histórico, entre otros casos. También representa una oportunidad para trabajar diversos enfoques como la interculturalidad, la equidad, las cuestiones género, los derechos de los pueblos indígenas y rurales, entre otros.

Cabe advertir sobre ciertos asuntos antes de continuar. Hay que tener precaución de equiparar "lo didáctico" con "lo lúdico" (Gómez y Rodríguez, 2014), priorizando actividades o juegos que, si bien mantienen el interés de los alumnos en su desarrollo, poco impactan si no tienen una finalidad específica. Es fundamental que las estrategias empleadas realmente movilicen y permitan la construcción de conocimientos, lo cual puede llevarse a cabo de distintos modos, como se ha descrito. La opción tampoco consiste en dejar de lado los contenidos históricos para dar énfasis a los intereses de los alumnos; si bien esto puede permitir una mayor atención e involucramiento (Brophy, 1998), no significa necesariamente la construcción del pensamiento histórico. Son aspectos que se deben trabajar de manera coordinada: aprovechar el interés para encauzarlo hacia las intenciones 
de la historia formativa a partir de los aspectos tanto motivacionales como cognitivos (Blumenfeld et al., 1991).

Hacer notar que menos aún se ha de cambiar la exposición de fechas y nombres por explicaciones que han hecho otros autores sobre los acontecimientos históricos, ya que al igual que se aprenden datos conceptuales, los jóvenes pueden llegar a mecanizar y repetir argumentos, dando un resultado similar al tradicional (Prats, 1989; Aisenberg, 1998). La apuesta es que sean ellos quienes a partir de las experiencias y el trabajo intelectual compartido con los otros y con el docente, generan conocimientos y explicaciones.

\subsection{Los recursos para apoyar la enseñanza y el aprendizaje}

Como recursos para apoyar las experiencias educativas contextualizadas, los docentes de secundaria cuentan con un amplio abanico de oportunidades, ya que la historia no se limita a lo que está plasmado en los libros de texto, sino que se encuentra en diferentes elementos que forman parte de la vida cotidiana. La elección dependerá en gran medida del docente, según las particularidades de su grupo y los recursos con que cuente a su disposición. La creatividad es un elemento significativo en la medida en que se buscan las formas de aprovechar lo que se encuentra disponible, incluyendo las fuentes o evidencias que se hallan en el hogar o la comunidad donde se ubica la escuela (Reyes, Jevey, Guerra, Palomo y Romero, 2009).

Al recorrer algunos sitios históricos, monumentos, zonas arqueológicas o acercarse a pinturas, fotografías, monedas, distintos objetos o réplicas, la historia resulta más vivencial. Las evidencias del pasado generan expectativas, curiosidad, motivación por tocarlas y acercarse a ellas y saber cuál es su origen, cómo la usaban - sobre todo cuando son objetos que "parecen extraños" - y quiénes lo usaban (Llonch y Parisi, 2016), o asombro al reconocer el pasado de algunos objetos que en el presente se usan de manera cotidiana (Cantonero, 2005). A partir del acercamiento a través de estos recursos que hablan de la forma en que vivían las personas en otros momentos históricos pero también aquellos que son cercanos a sus padres o abuelos - los alumnos pueden darse cuenta que la historia es algo adyacente a las personas, no algo artificial, y que se puede encontrar en diferentes espacios, como las casas o edificios, pues son evidencias de otros momentos. También comprenderán que aquellas producciones que se realizan en el presente, en algún momento del futuro podrían ser empleadas como fuentes para explicar cómo vivían las personas. Así, el contacto directo con objetos, además de la atracción que genera en los alumnos con mayor facilidad (Santacana y Llonch, 2008), permiten hacen reconstrucciones acerca de aquello que existió en el pasado.

En el caso, por ejemplo, de visitar algún espacio, se debe considerar que esto no consiste en ir a un museo, sala o sitio arqueológico a copiar las fichas de identificación que acompañan lo exhibido. Estos lugares permiten acercar a los jóvenes a la posibilidad de observar, tocar, manipular -en algunos casos, como la excavación de yacimientos arqueológicos simulados (Bardavio y Mañé, 2017) - y recorrer los restos, lo cual les confiere un atractivo didáctico importante (Rivero, 2008). Implica el acercamiento a un sitio con evidencias acerca del pasado para explorarlo, sorprenderse de lo que ahí hay, contrastar los objetos exhibidos con los que usan en su vida cotidiana, tratar de entender cómo vivían las personas de ese lugar -buscar reconstruir su vida-, entre otros cuestionamientos, que fomentan la imaginación, pero que permiten contrastar aquello que piensan con las evidencias que se les presenten. El realizar una investigación previa ayuda a que se tenga una mejor comprensión y aprovechamiento de la visita, identificando aquellos aspectos que pudieran resultar más atractivos o aprovecharse de una forma más didáctica. Es de utilidad preparar preguntas o un problema a resolver a partir de lo que se observará en el lugar para explotar la potencialidad educativo que tienen estos recursos (Egea, Pernas y Arias, 2014).

No menos trascendente a este patrimonio material como recurso para el estudio de esta asignatura, es el uso de lo inmaterial e intangible (Prats, 2014) como las manifestaciones culturales plasmadas en la música, los rituales, las técnicas, las leyendas, etcétera, que forman parte de la 
identidad colectiva y de la historia de algunas comunidades. A la par de acercarse a los conocimientos históricos, se alienta en los estudiantes el sentido de pertenencia al contexto local (Roberts, 2011) y se favorece la preservación de aquellos elementos del pasado que forman parte de su historia y de los demás.

\subsection{La evaluación formativa del pensamiento histórico}

Desde el constructivismo se propone que la evaluación no debe desvincularse de los otros momentos del proceso educativo. Tradicionalmente se le ha asociado con la obtención de una calificación expresada en un número, lo cual deja de lado información útil que puede proporcionar para los procesos de enseñanza y aprendizaje. Investigaciones realizadas en España por Muñoz y Martínez (2011), Miralles, Gómez y Sánchez (2014), Monteagudo et al. (2015) y Gómez y Miralles (2016) respecto a la evaluación en la asignatura de historia en las escuelas han dado cuenta de que los procedimientos y criterios que se emplean continúan apelando a la finalidad "objetiva" de los instrumentos cerrados y cuyo principal recurso es el libro de texto, dando especial relevancia a los conceptos de una forma descontextualizadas.

Estas prácticas, cuya preocupación central es la memorización y recitación de hechos, poco abonan a la construcción de la capacidad para pensar históricamente (VanSledright, 2004). Los resultados no son exclusivos de aquel país, pues en México la evidencia empírica muestra que la situación de la evaluación en la asignatura de historia es igual en los sentidos señalados. Las prácticas tradicionales de enseñanza se traducen en formas similares de evaluación donde la recuperación de la memoria de forma fidedigna ("tal cual lo dice el libro") es muestra de que se ha aprendido.

Si como se ha dicho anteriormente, la historia representa una asignatura con un potencial social importante en la formación de ciudadanos comprometidos, esto hace necesario construir una cultura de la evaluación que ayude a conocer -tanto a alumnos como a docentes- los obstáculos y progresos que van surgiendo en los procesos de enseñanza y aprendizaje (Letelier, 2009). Implica llevar a cabo una evaluación significativa de habilidades y capacidades y no tanto de conocimientos conceptuales (Miralles et al., 2014).

La evaluación debe considerarse desde su parte formativa, a lo largo de todo el proceso y no sólo al final del mismo, brindando información tanto a alumnos como docentes acerca del desempeño y la forma en que se están llevando a cabo la enseñanza y el aprendizaje, permitiendo de este modo mejorar las actividades docentes e incrementar el rendimiento escolar del alumnado (Alfageme, Miralles y Monteagudo, 2011). A los jóvenes les permite observar cómo han desarrollado sus conocimientos, habilidades, valores y actitudes, y mediante la retroalimentación -y en conjunto con el docente- elaborar compromisos que permitan mejorar sus procesos, a partir de la orientación y motivación (Alfageme y Miralles, 2009). Considerando los diferentes actores que intervienen en la evaluación, es posible su participación al valorar el trabajo de sus compañeros, tanto de equipo como de grupo, así como su propio desempeño (coevaluación y autoevaluación).

Al docente le brinda información acerca de cómo ingresan los alumnos al inicio, qué fortalezas o debilidades tienen, cómo evolucionan a lo largo del proceso, qué información o conocimientos previos tienen acerca de los contenidos, qué necesita para mejorar el proceso cuando los resultados no son los esperados o para seguir desarrollándolos cuando han sido propicios, entre otros datos. Desde el inicio del proceso la evaluación diagnóstica permite no sólo conocer "cómo vienen los alumnos", sino también sus ideas, creencias, percepciones, inquietudes, intereses, dificultades y oportunidades, las cuales deben retomarse de manera constante para darles seguimiento y observar cómo evolucionan, y no solamente cumplir con el requisito administrativo como en algunos casos pasa (por ejemplo el llamado "examen diagnóstico" para el expediente, práctica muy extendida en México e incluso solicitada por algunas autoridades educativas como requisito).

Uno de los retos que el docente enfrenta durante la evaluación es cómo evaluar y qué evaluar, pues puede caer en contradicciones que lleven su práctica nuevamente a cuestiones tradicionales. 
Sustancial es la congruencia entre lo que se enseña y lo que se evalúa, pues de esta forma habrá correspondencia y se favorecerá de manera adecuada que los alumnos tengan una formación integral. Hay que considerar en los resultados académicos los contextos específicos en que se desarrolla el hecho educativo (Kalman y Carvajal, 2007) teniendo en cuenta los materiales, los recursos disponibles, los contenidos y la forma en que se dan las interacciones en el aula. Todos estos son factores que pueden incidir en los procesos y en sus resultados, pues ante la falta de algunos recursos didácticos o la desvinculación de un contenido con el contexto, por ejemplo, los aprendizajes pueden verse limitados.

La evaluación debe tener en cuenta la puesta en práctica de conocimientos y habilidades, así como de valores y actitudes que se trabajaron a lo largo de los procesos. Al situar el conocimiento y contextualizarlo como se hizo a partir de las estrategias y con el apoyo de las herramientas mencionadas, la evaluación tendrá un carácter más relevante. Se volverá una evaluación auténtica (Díaz-Barriga, 2005) en la cual se destacará la movilización de las capacidades, así como la vinculación y la aplicación en situaciones y contextos de la vida real.

Referirse a situaciones de la vida real o situaciones auténticas (Svinicki, 2004) no sólo significa que el alumno sepa "hacer algo en la calle" o "fuera de la escuela", sino que demuestre su nivel de desempeño a través de la comprensión, la solución o intervención en cuestiones sociales, tanto personales como en diferentes escalas, similares a las que enfrentará el algún momento. $O$ bien, aquellas que, aunque no forman parte directa de su vida cotidiana, son representativas del contexto y momento histórico en que viven.

Se debe favorecer en las clases de Historia que el alumno sea capaz de analizar su presente desde una perspectiva histórica, formular explicaciones, establecer comparaciones, identificar cambios o permanencias, explicar causas y consecuencias, a fin de generar argumentos fundamentados y críticos acerca de lo que ocurre a su alrededor. Un aspecto clave en la preparación de los docentes de secundaria -tanto en su formación inicial como continua- es impulsar su papel como promotores de cambio social a través de la enseñanza de la historia en las aulas, buscando que no limiten su función a la mera reproducción de saberes desvinculados y descontextualizados, sino considerando las condiciones en que se encuentran situados y reflexionando con base en ello (Monter, 2013). Al proponer el desarrollo del pensamiento histórico en los alumnos, es necesario considerar el mismo en los docentes, quienes, mediante las experiencias de aprendizaje y la reflexión compartida en el aula, pueden generar conciencia social para la convivencia y la problematización de situaciones sociales de su contexto.

En este sentido de la evaluación, es una contradicción remitirse al empleo de pruebas cerradas o con respuestas únicas que exigen el "vaciado" de datos e información. Esto resulta poco apropiado, ya que limitan en mucho lo que los alumnos probablemente han desarrollado, y sus opiniones, ideas, explicaciones o argumentos no tendrán cabida como parte del proceso evaluativo. Un replanteamiento en estas pruebas puede ser con el empleo de ejercicios que movilicen capacidades de una forma más compleja al manejar e interpretar diversas fuentes, resolver problemas y reflexionar acerca de cuestiones del presente a partir de los procesos y acontecimientos del pasado (Gómez y Miralles, 2016).

Diferentes estrategias y recursos son útiles para este momento a partir de ejercicios de simulación, ensayos, análisis hemerográfico, estudios de casos, proyectos de investigación, entre otros, que pueden ser valorados en un sentido formativo y remiten a los jóvenes a la movilización de múltiples y complejas capacidades. El uso de la narrativa ha adquirido especial importancia en propuestas didácticas para la enseñanza de la historia (Gómez y Miralles, 2016). La redacción implica no sólo saber comunicar con claridad una idea, sino elaborar la argumentación con base en lo encontrado en las fuentes y poner en juego los conocimientos adquiridos (Valle, 2011); es decir, habilidades relacionadas con el pensamiento histórico (Gómez y Miralles, 2015). Con estos ejercicios, el docente podrá recuperar información acerca de las competencias de los estudiantes, pero a la vez posibilita entender cómo desarrollan sus procesos, las progresiones que tienen, las dificultades que presentan, la forma en que analizan la relevancia histórica (Seixas y Morton, 2013) 
de los proceso y acontecimientos y la manera en que los vinculan con su vida cotidiana.

\section{Reflexiones finales}

El trabajo ha querido exponer la importancia de contextualizar los procesos de enseñanza y aprendizaje en la educación secundaria a fin de generar aprendizajes situados y significativos como parte del estudio de una historia formativa. Es necesario considerar aquello que ocurre en el contexto en que se dan las prácticas educativas teniendo en cuenta la diversidad que existe en las aulas, la cual se expresa no sólo en el origen étnico o social de los jóvenes, sino en sus intereses, ideas, percepciones, debilidades y fortalezas.

Hay que reconocer que este planteamiento tiene posturas encontradas (Zabalza, 2012), a saber: que hay argumentos que señalan que la escuela no debe centrarse en la vida de los alumnos, sino precisamente trascender esta escala y ampliar las posibilidades para conocer campos más amplios; o que existen aspectos que difícilmente pueden contextualizarse debido a la complejidad que representan.

A partir de las bondades antes expuestas sobre la contextualización de los contenidos de historia, se puede afirmar que es relevante en los procesos de enseñanza y aprendizaje. Esto se debe a que permite la construcción de aprendizajes significativos en los alumnos, mediante experiencias educativas y la intervención docente, donde el partir del entorno de los estudiantes no resulta una limitante, o ceñirse a sólo éste, sino se toma como base para poder comprender otros espacios en conjunto de forma gradual y cada vez más compleja.

Asimismo, se favorecerá que los jóvenes aprendan a mirar con "ojos históricos" (Domínguez, 1989) y desarrollen el deseo por seguir aprendiendo acerca de su sociedad, pues tendrán las bases para seguir construyendo y reconstruyendo sus explicaciones acerca de lo que ocurre en su contexto, país y mundo, ya que los procesos situados habrán sentado bases para desarrollar ese tipo de ejercicios en la vida fuera de la escuela. Contrario a lo que ocurre cuando se ha "digerido" la información por ellos y se les otorga como producto ya terminado, la experiencia y acercamiento desde lo que les es cercano permite la generación de un proceso formativo. Se comparte el planteamiento de Bravo (2009, p. 6), cuando menciona que "el riesgo de seguir enseñando una historia al margen de las experiencias de los estudiantes es la continuidad de una historia escolar que es asumida por los alumnas y alumnos del sistema escolar desde el sin sentido para la vida que «habitan»".

Pensar en una práctica con y para los alumnos, implica un desafío para los docentes, que, sin embargo, favorece el desarrollo de conocimientos, valores, actitudes y habilidades encaminados a pensar históricamente y desarrollar una conciencia para la convivencia. El docente de secundaria deberá convertirse en un "profesor investigador social" (Barca, 2012) que busque atender la progresión de sus estudiantes a partir de una intervención sostenida basada en el registro de sus observaciones y el trabajo constante.

Un planteamiento de este tipo representa un desafío trascendente, no sólo en el sentido didáctico, sino en relación a la función de la historia, pues cuando se plantea la experiencia educativa de forma tradicional y ajena a lo que ocurre en el contexto, se corre el riesgo de la pérdida de la identidad y del sentido de pertenencia de los jóvenes quienes ven lejano y distante aquello que se busca que aprendan, a la par que se sesga parte de su realidad.

Ante esto, hay que considerar transformaciones en las prácticas educativas que ocurren en las aulas teniendo en cuenta modificaciones constantes con base en las necesidades e intereses de los alumnos (conforme se vayan dando progresiones paulatinas), y superando visiones tradicionales que enfatizan en la acumulación de conocimientos, sobre todo en una asignatura con grandes posibilidades para favorecer la comprensión del mundo social. Por este motivo, contextualizar el aprendizaje resulta necesario a fin de generar procesos que resulten significativos. En la medida en que se avanza a través de los diferentes trayectos, el conocimiento se hace cada vez más complejo.

La toma de conciencia por parte de los docentes, así como de la responsabilidad con la 
formación de sus alumnos es trascendental, pues de este modo encaminará su práctica a la formación de futuros ciudadanos comprometidos, críticos y activos en relación con su mundo cercano e incluso con lo que ocurre en otros espacios.

\section{Bibliografía}

Aisenberg, B. (1994). Para qué y cómo trabajar en el aula con los conocimientos previos de los alumnos: un aporte de la psicología genética a la didáctica de estudios sociales para la escuela primaria. En S. Alderoqui y B. Aisenberg (coords.), Didáctica de las ciencias sociales: aportes y reflexiones (pp. 137-162). España: Paidós.

Aisenberg, B. (1998). Didáctica de las ciencias sociales: ¿desde qué teorías estudiamos la enseñanza? Revista de Teoría y Didáctica de las Ciencias Sociales, 3, 136-163.

Alfageme, M. B. y Miralles, P. (2009). Instrumentos de evaluación para centrar nuestra enseñanza en el aprendizaje de los estudiantes. Íber. Didáctica de las Ciencias Sociales, Geografía e Historia, 60, 8-20.

Anijovich, R., Malbergier M. y Sigal, C. (2007). Una introducción a la enseñanza para la diversidad. Aprender en aulas heterogéneas. Buenos Aires: Fondo de Cultura Económica.

Arista, V. (2011). Cómo se enseña la historia en la educación básica. En J. Vázquez (coord.), Enseñanza y aprendizaje de la Historia en la Educación Básica (pp. 105-125). México: Secretaría de Educación Pública.

Ausubel, D., Novak, J. y Hanesian, H. (2009). Psicología Educativa, un punto de vista cognoscitivo. México: Trillas.

Barca, I. (2012). Ideias chave para uma Educação Histórica: uma busca de (inter) identidades. História Revista, 17 (1), 37-51.

Bardavio, A. y Mañé, S. (2017). La arqueología en la enseñanza obligatoria. El ejemplo del campo de aprendizaje de La Noguera. Revista Otarq, 2, 331-345.

Blumenfeld, P., Marx, R., Patrick, H., Krajcik, J. y Soloway, E. (1997). Teaching for understanding. En B. Biddle, T. Good e I. Goodson (eds.), International Handbook of Teachers and Teaching (pp. 819-878). Dordrecht: Kluwer Academic.

Blumenfeld, P., Soloway, E., Marx, R., Krajcik, J., Guzdial, M. y Palincsar, A. (1991). Motivating project-based learning: Sustaining the doing, supporting the learning. Educational Psychologist, 26 (3-4), 369-398. doi.org/10.1080/00461520.1991.9653139

Bravo, L. (2009). ¿Desde dónde enseñar historia? Recuperado de https://profesorgerardou.files. wordpress.com/2009/12/desde-donde-ensenar-historia.pdf

Brophy, J. (1998). Motivating students to learn. Boston: McGraw-Hill.

Canals, R. (2013). Estrategias didácticas para una enseñanza competencial de las ciencias sociales en la educación obligatoria. En J. Pagès y A. Santisteban (eds.), Una mirada al pasado y un proyecto de futuro. Investigación e innovación en didáctica de las ciencias sociales (pp. 371380). Barcelona: Universitat Autònoma de Barcelona/Asociación Universitaria de Profesorado de Didáctica de las Ciencias Sociales.

Cantonero, J. (2005). Una aproximación didáctica a la historia de España a través de la numismática. Tras los rastros de la iconografía liberal y nacional en la moneda española decimonónica. Íber: Didáctica de las Ciencias Sociales, Geografía e Historia, 44, 96-113.

DeLott, E., Hope, L y Karandjeff, K. (2009). Contextualized Teaching \& Learning: A Faculty Primer. California: State Wide Academic Senate.

Dewey, J. (2010). Experiencia y educación. Madrid: Biblioteca Nueva.

Díaz-Barriga, F. (2003). Cognición situada y estrategias para el aprendizaje significativo. Revista Electrónica de Investigación Educativa, 5 (2), 105-117.

Díaz-Barriga, F. (2005). Enseñanza situada. Vínculo entre la escuela y la vida. México: Mc Graw Hill. Domínguez, J. (1986). Enseñar a comprender el pasado histórico: conceptos y «empatía». Infancia y Aprendizaje, 34, 1-21. 
Domínguez, J. (1989). El lugar de la historia en el currículum 11-16. Un marco general de referencia. En M. Carretero, J. I. Pozo y M. Asensio (comps.), La enseñanza de las Ciencias Sociales (pp. 33-60). Madrid: Visor.

Donovan, M. S., Bransford, J. D., y Pellegrino, J. W. (eds.). (1999). How People Learn: Bridging Research and Practice. Washington D.C.: National Academy Press.

Egea, A., Arias, L., y Clares, M. E. (2017). Historia a ritmo de rap. Una propuesta interdisciplinar para la enseñanza de las Ciencias Sociales y la Educación Artística. Espiral. Cuadernos del Profesorado, 10 (20), 51-57.

Egea, A., Pernas, S., y Arias, L. (2014). Re-construyendo la historia a partir del patrimonio arqueológico. En O. Fontal, A. Ibáñez-Etxeberria y L. Martín (coords.), Reflexionar desde las experiencias. Una visión complementaria entre España, Francia y Brasil. Actas del II Congreso Internacional de Educación Patrimonial. Madrid: Observatorio de Educación Patrimonial en España/Instituto del Patrimonio Cultural de España.

Gillespie, M. (2002). EFF research principle: A contextualized approach to curriculum and instruction. EFF Research to Practice Note, 3, 2-8.

Gómez, C. J. y Miralles, P. (2015) ¿Pensar históricamente o memorizar el pasado? La evaluación de los contenidos históricos en la educación obligatoria en España. Revista de Estudios Sociales, $52,52-68$.

Gómez, C. J. y Miralles, P. (2016). Las competencias históricas en educación obligatoria: evaluación, estrategias basadas en la indagación, y argumentación de los estudiantes. Journal of New Approaches in Educational Research, 5 (2), 139-146.

Gómez, C. J. y Rodríguez, R. A. (2014). Aprender a enseñar ciencias sociales con métodos de indagación. Los estudios de caso en la formación del profesorado. REDU: Revista de Docencia Universitaria, 12 (2), 307-325.

Gómez, C. J., Miralles, P. y Molina, S. (2015). Evaluación, competencias históricas y educación ciudadana. Revista de Estudios Sociales, 52, 9-14.

Gómez, C. J., Ortuño, J. y Molina, S. (2014). Aprender a pensar históricamente. Retos para la historia en el siglo XXI. Revista Tempo e Argumento, 6 (11), 5-27.

Kalman, J. y Carvajal, E. (2007). Hacia una contextualización de la enseñanza y el aprendizaje en las aulas de la Telesecundaria. Revista Latinoamericana de Estudios Educativos, 37 (3-4), 69-106.

Kenea, A. (2014). The practice of curriculum contextualization in selected primary schools in rural Ethiopia. Journal of Education and Practice, 5 (10), 49-56.

Kirk, B. (2012). Designing a creative contextualized primary curriculum. Nottingham: National College for School Leadership.

Kolb, D. (1984). Experiential Learning: Experience as the source of learning and development. New Jersey: Prentice Hall.

Letelier, M. E. (2009). La evaluación de aprendizajes de personas jóvenes y adultas. Revista Iberoamericana de Evaluación Educativa, 2 (1), 147-161.

Llonch, N. y Parisi, V. (2016). Contribuciones a la didáctica de la Historia a través del método de análisis del objeto: como ejemplo... una "vasulla". Panta Rei. Revista Digital de Ciencia y Didáctica de la Historia, 111-124.

Mazzeo, C., Rab, S. Y. y Alssid, J. L. (2003). Building bridges to college and careers: Contextualized basic skills programs at community colleges. Brooklyn: Workforce Strategy Center.

Miralles, P., Gómez C. J. y Sánchez, R. (2014). Dime qué preguntas y te diré qué evalúas y enseñas. Análisis de los exámenes de ciencias sociales en tercer ciclo de Educación Primaria. Aula Abierta, 42, 83-89.

Monteagudo, J., Molina, S. y Miralles, P. (2015). Opiniones sobre evaluación de los profesores de segundo ciclo de ESO de Geografía e Historia en España. El caso de la Región de Murcia. Revista Mexicana de Investigación Educativa, 20 (66), 737-761.

Monter, R. (2013). Educación histórica en la Licenciatura en Educación primaria en la BENM 
[Benemérita Escuela Normal de México]. En X. Rodríguez, A. Toriz y M. Acevedo (comps.), Tercer Encuentro Nacional de Docencia, Difusión y Enseñanza de la Historia y Primer Encuentro Internacional de la Enseñanza de la Historia (pp. 756-770). México: Universidad Pedagógica Nacional.

Muñoz, C. y Martínez, R. (2011). La evaluación de los contenidos curriculares en las aulas de segundo ciclo de la Educación general básica. En P. Miralles, S. Molina y A. Santisteban (eds.), La evaluación en el proceso de enseñanza y aprendizaje de las ciencias sociales (pp. 327-348). Murcia: Asociación Universitaria del Profesorado de Didáctica de las Ciencias Sociales.

Pagés, J. (2004). Enseñar a enseñar historia: la formación didáctica de los futuros profesores de historia. En E. Nicolás y J. A. Gómez (coords.), Miradas a la Historia (pp. 155-178). España: Universidad de Murcia.

Perafán, A. (2013). Reflexiones en torno a la didáctica de la historia. Revista Guillermo de Ockham, $11(2), 149-160$.

Perin, D. (2011). Facilitating student learning through contextualization: A review of evidence. Community College Review, 39 (3), 268-295. doi.org/10.1177/0091552111416227

Perkins, D. (1995). La escuela inteligente. Barcelona: Gedisa.

Piaget, J. (1991). Seis estudios de psicología. Barcelona: Labor.

Prats, J. (1989). Las experiencias didácticas como alternativas al cuestionario oficial: reflexiones críticas sobre las experiencias "Germania-75" e "Historia 13-16". En M. Carretero, J. I. Pozo y M. Asensio (comps.), La enseñanza de las Ciencias Sociales (pp. 201-210). Madrid: Visor.

Prats, J. (2014). Patrimonio y educación cívica. Her\&Mus, 6 (2), 5-6.

Prats, J. y Santacana, J. (2011) ¿Por qué y para qué enseñar historia? En J. Vázquez (coord.), Enseñanza y aprendizaje de la Historia en la Educación Básica (pp. 18-68). México: Secretaría de Educación Pública.

Quintero, M. A. (2016). Retos y posibilidades de la enseñanza de la historia en Colombia: Lecciones del caso mexicano. Revista Cambios y permanencias, 2, 617-637.

Reyes, J. I., Jevey, A., Guerra, S., Palomo, A. G. y Romero, M. (2009). Estrategias de enseñanza y aprendizaje de la historia en la escuela. La Habana: Ministerio de Educación.

Rivero, M. P. (2008). Propuesta para una integración del patrimonio arqueológico en el nuevo currículo de educación primaria. En R. M. Ávila, A. Cruz y M. C. Diez (eds.), Didáctica de las Ciencias Sociales, currículo escolar y formación del profesorado. La didáctica de las Ciencias Sociales en los nuevos planes de estudio (pp. 391-400). Andalucía: Universidad de Jaén.

Rivet, A. E. y Krajcik, J. S. (2008). Contextualizing instruction: Leveraging students' prior knowledge and experiences to foster understanding of middle school science. Journal of Research in Science Teaching, 45 (1), 79-100.

Roberts, P. (Marzo, 2011). From Historical Literacy to a Pedagogy of History. Trabajo presentado en el National Symposium Building Bridges for historical learning: connecting teacher education and museum education, Canberra, Australia. Recuperado de http://www.canberra.edu.au/ researchrepository/file/3d3fb227-73c7-dc08-49ee-275fa23092d3/1/full text final.pdf

Rodríguez, M. L. (2004). La teoría del aprendizaje significativo. Conference on Concept Mapping. Pamplona, España. Recuperado de http://cmc.ihmc.us/papers/cmc2004-290.pdf

Romero, M. (2010). El aprendizaje experiencial y las nuevas demandas formativas. Revista de Antropología Experimental, 10, 89-102.

Sáiz, J. (2013). Alfabetización histórica y competencias básicas en libros de texto de historia y en aprendizaje de los estudiantes. Didáctica de las Ciencias Experimentales y Sociales, 27, 4366.

Santacana, J. (2005). Reflexiones en torno al laboratorio escolar en Ciencias Sociales. Íber. Didáctica de las Ciencias Sociales, Geografía e Historia, 43, 7-14.

Santacana, J. y Llonch, N. (2008). Museo local. La cenicienta de la cultura. Barcelona: Trea.

Santacana, J., Martínez, T. Llonch, N. y López, V. (2016). ¿Qué opinan los adolescentes sobre los 
museos y la didáctica? Didáctica de las ciencias experimentales y sociales, 31 (2), 23-38.

Seixas, P. y Colyer, J. (2012). Assessment of Historical Thinking. A Report on the National Meeting of the Historical Thinking Project. Vancouver: Centre for the Study of Historical Consciousness.

Seixas, P. y Morton, T. (2013). The Big Six Historical Thinking Concepts. Toronto: Nelson Education.

Squire, K., Makinster, J., Barnett, M., Luehmann, A. y Barab, S. (2003). Designed curriculum and local culture: Acknowledging the primacy of classroom culture. Science Education, 87, 468489. doi.org/10.1002/sce.10084

Svinicki, M. D. (2004). Learning and motivation in the postsecondary classroom. San Francisco: Jossey-Bass.

Taylor, T. y Young, C. (2003). Making History: A guide for the teaching and learning of history in Australian schools. Melbourne: Curriculum Corporation.

Valle, A. (2011). El uso de las fuentes escritas en la enseñanza de la Historia. Análisis de textos escolares para tercero y cuarto de secundaria. Educación, 20 (38), 81-106.

VanSledright, B. A. (2004). What does it mean to think historically... and How do you teach it? Social Education, 68 (3), 230-233.

Vázquez, F. (2013). Posturas epistémicas de la Historia en estudiantes de la licenciatura en educación primaria en el marco de trabajo con una situación problema (tesis de doctorado). Universidad Nacional Autónoma de México, México.

Vygotsky, L. S. (1979). El desarrollo de los procesos psicológicos superiores. Buenos Aires: Grijalbo.

Wineburg, S., Smith, M., y Breakstone, J. (2012). New directions in assessment: Using Library of Congress sources to assess historical understanding. Social Education, 76 (6), 288-291.

Zabalza, M. (2012). Territorio, cultura y contextualización curricular. Interacções, 22, 6-33. 


\section{Panta Rei}

PANTA REI es una revista digital de investigación orientada a la Historia y otras ciencias afines. Su principal objetivo es la transmisión del conocimiento científico, dando una oportunidad también a los jóvenes investigadores que quieren abrirse camino en el estudio de las ciencias humanas y sociales. Se compone de estudios originales relacionados con la disciplina histórica así como su didáctica y difusión. Las diferentes secciones que componen la revista son: artículos de investigación, entrevistas a profesionales, recensiones de monografías de actualidad y crónicas de congresos o eventos científicos relevantes.

Todos los artículos publicados son objeto de un proceso de revisión a cargo de un mínimo de dos evaluadores, que se consideran expertos en el ámbito temático del artículo propuesto. Nuestro deseo es poder ofrecer unos contenidos rigurosos, de calidad y de interés.

EI CEPOAT (Centro de Estudios del Próximo Oriente y la Antigüedad Tardía de la Universidad de Murcia) es la institución encargada de la coordinación y gestión de la revista, desde donde anualmente se lanzará la convocatoria para aquellos que estén interesados en publicar sus trabajos, siempre relacionados con la Historia, Arqueología, Historia del Arte, Didáctica de las Ciencias Sociales, etc.

PANTA REI is a digital journal focused on History and other sciences related to it. Its main objective is the transmission of scientific knowledge by giving also an opportunity to young researchers who want to make their way in the study of human and social sciences. It is composed by original studies related to History, as well as its didactics and promotion. The different sections of this journal are: research articles, interviews to professionals, recensions on monographs about current issues and reports about congresses or relevant scientific events.

All the articles published are subject to a revision process carried out by a minimum of two reviewers who are considered to be experts in the field of the article proposed. Our wish is to offer rigorous contents with quality and being of interest to the reader.

CEPOAT (Centre of Studies of the Middle East and Late Antiquity of the University of Murcia) is the institution in charge of the coordination and management of this journal. This is the centre from where the call for papers will be launched for all the people interested in publishing their papers, always related to History, Archeology, Art History, Didactics of the Social Sciences, etc. 


\section{Normas de Publicación}

El autor se compromete a enviar trabajos originales, que no se encuentren publicados en otras revistas ni en otros idiomas. Así mismo, el mismo artículo no podrá ser presentado en otras revistas mientras dure el proceso de evaluación.

\section{Envío y presentación de originales}

Los artículos se enviarán exclusivamente a través del correo electrónico a la dirección pantarei@um.es. Los textos serán enviados en formato DOC y las imágenes en formato JPEG o TIFF, y con un tamaño mínimo de 2000 px. Éstas no aparecerán incorporadas en el texto, sino enviadas en archivo aparte y correctamente numeradas según su posición en el texto. Junto al trabajo, se rellenará y enviará un documento aparte en el que se especifiquen los datos del autor siguiendo el modelo disponible en la página Web de la revista.

Para la redacción de los trabajos se tendrá en cuenta el Manual de la American Psychological Association, en su sexta edición. La extensión máxima de los trabajos será de 30 páginas. La tipografía será Arial 11, con interlineado sencillo y sin espacio alguno entre párrafos. El texto deberá ir justificado a ambos márgenes y sin sangría en los primeros párrafos. Los márgenes serán de $2,50 \mathrm{~cm}$. En los casos en los que fuera necesario incorporar notas, éstas irán a pie de página, enumeradas consecutivamente, con tipografía Arial 10, interlineado sencillo y justificadas a ambos márgenes.

Una información más detallada se encuentra disponible en la página http://www.um.es/cepoat/ pantarei.

\section{Proceso de valoración y evaluación}

Una vez recibidos los trabajos, la Revista realizará una primera valoración. Si el trabajo enviado se ajusta a las normas de presentación propuestas, la temática es coincidente con la línea editorial de la revista y posee la calidad científica necesaria, será remitido al consejo asesor para una primera evaluación. Si no es así en este primer paso se puede rechazar directamente los documentos que incumplan claramente la línea editorial.

Será el Consejo Asesor quien indique a la revista la originalidad, relevancia, estructura, redacción, aparato bibliográfico, etc. del trabajo enviado y, para ello, se designará a dos revisores expertos externos que evaluarán cada uno de los trabajos, que pueden formar parte (o no) de este Consejo Asesor. La selección de los revisores se ajustará a la temática y características metodológicas del trabajo. El nombre y filiación de los autores serán eliminados del trabajo para su revisión, así como los revisores actuarán de manera anónima y confidencial.

Los revisores deberán rellenar un informe de evaluación que centrará su atención en aspectos tales como características formales, originalidad y novedad de los trabajos, relevancia de las propuestas y los resultados, calidad metodológica y validez científica.

Una vez terminado el proceso se decidirá la aceptación o no de los mismos y su publicación en el número que sea pertinente, así como las modificaciones susceptibles de ser realizadas para su final publicación. Dicha notificación se enviará únicamente por correo electrónico, en un plazo máximo de seis meses. 


\section{Publishing rules}

The author is committed to submit original papers not having been published in other reviews or in other languages. In this way, it is not allowed for the same paper to be presented in other reviews during the evaluation process.

\section{Submission and presentation of originals}

The articles will be exclusively submitted by email to pantarei@um.es. The texts will be submitted in DOC format and the images in JPEG or TIFF format, and with a minimum size of 2000 px. Images will not be integrated in the text but sent in another file and properly numbered according to their position in the text. Attached to the paper, a document will be filled out and sent where the author's data will be specified following the model available on the website.

The sixth edition of the Manual of the American Psychological Association will be taken into account for the writing of the papers. The length of the papers must not exceed 30 pages. Typography will be Arial 11 , with simple line spacing and no space between paragraphs. The text must be justified on both margins without indentation in the first paragraphs. Margins size will be $2.50 \mathrm{~cm}$. Where it could be necessary the incorporation of notes, they will be at the bottom of the page, consecutively numbered with typography Arial 10, simple line spacing and justified on both margins.

More detailed information is available on the website: http://www.um.es/cepoat/pantarei.

\section{Examination and assessment process}

The Journal will submit the papers to a first examination once received. If the paper follows the presentation guidelines, the subject agrees with the editorial line of this journal, and possess the scientific quality required, it will be sent to the advisory council for a first assessment. If not, the documents which clearly fail to complete the editorial line may be rejected straightaway in this first step.

The Advisory Council will indicate the originality, relevance, structure, writing, bibliography, etc. of the text to the journal; for this purpose, two outside experts will be designated to review the papers; these experts can be (or not) part of this Advisory Council. The selection of the experts will adjust to the subject and methodological characteristics of the paper. Name and affiliation of the author will be eliminated from the text for its review, in this way experts will act anonymously and confidentially.

The experts will fill out an assessment report which will focus on aspects such as formal characteristics, originality and novelty of the papers, relevance and results of the proposal, methodological quality and scientific validity.

Once the process is finished, the acceptance or not of the papers and its publication in the corresponding edition will be decided, as well as the modifications that may be done for its final publication. This notification will be sent by email within 6 months maximum. 


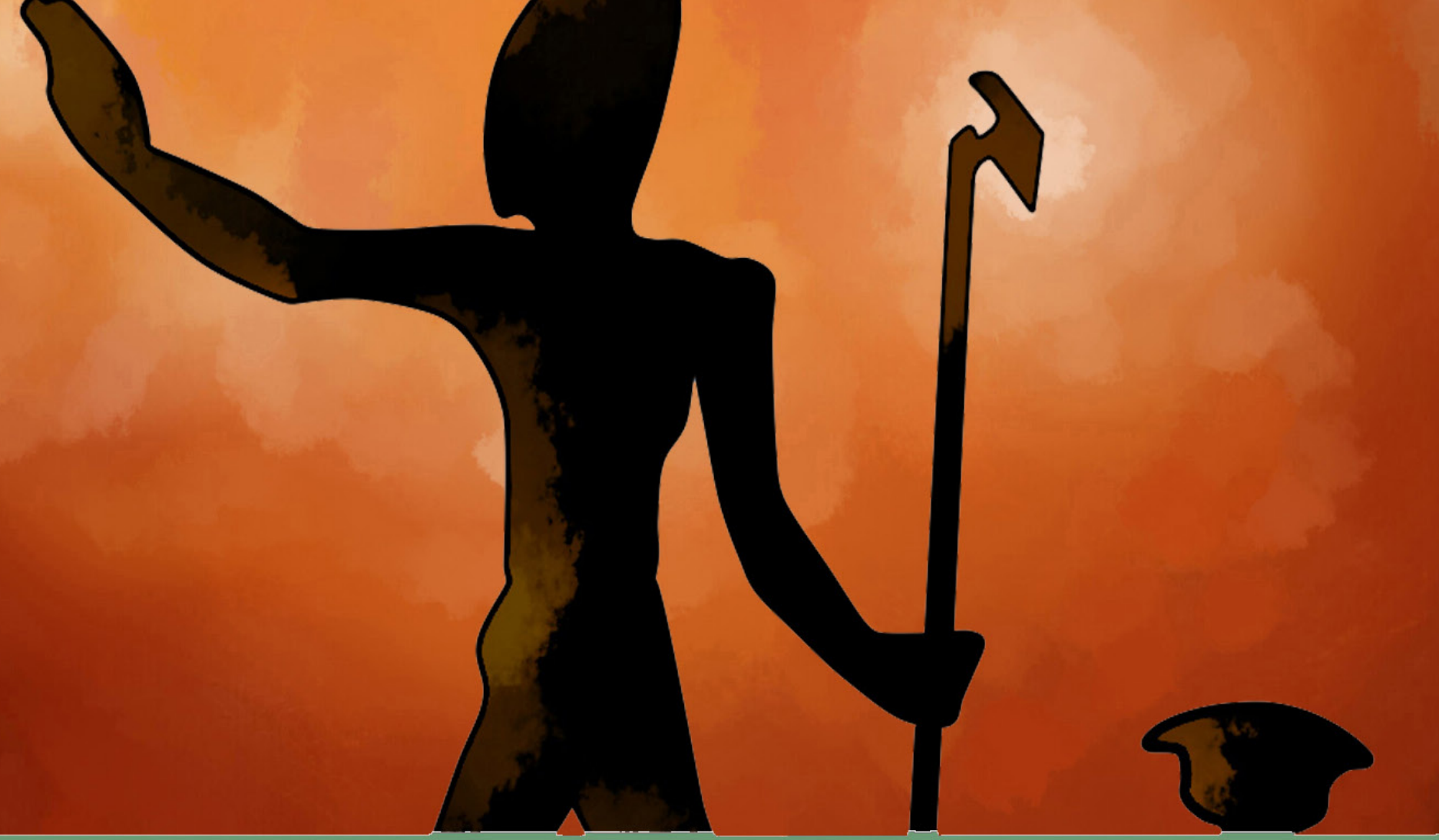

\section{cepot}

UNIVERSIDADD DE MURCIA

centro de estudios del

próximo oriente y la

antigüedad tardía 